disk. The distribution of pseudolipomas by age-groups emphasizes the importance of the thickness of the breast disk. The pseudolipomas were found in four pre-menopausal and 14 post-menopausal women with cancer, a ratio of 1 to 3.5. This ratio is far higher than the ratio of 1 to 1.8 for the pre-menopausal to post-menopausal distribution of cancer found by Bonser et al. (1961, p. 351) in a series of 220 unselected breast cancers. The breast substance is 2 to $4 \mathrm{~cm}$. thick in the pre-menopausal woman, but after the menopause it is often reduced to a thin sheet, less than $0.5 \mathrm{~cm}$. in thickness. Clearly the cancer which starts in the thin postmenopausal breast can more readily affect the overlying fibrous septa.

Although carcinomatous infiltration of the fibrous septa has been observed in this series it plays little part in the production of the pseudolipoma. When it occurs it produces firm adherence of the skin to the tumour.

The oedema produced by the chronic inflammatory reaction in and around the expanded cancers seems the likely explanation of the production of the overlying pseudolipoma. When oedema is produced by severe or acute inflammation it may be so intense that oedema of the skin results.

A swelling which was sufficiently defined to be easily felt under the pseudolipoma was found in 11 out of 18 cases, but a confident diagnosis of cancer could not have been made from physical examination except in three of these where the overlying skin was adherent. When an indefinite swelling was present under the pseudolipoma the cancer could have been entirely missed, and there were three patients with cancer in whom the only physical sign was the pseudolipoma. Conversely, in one of the patients in whom duct ectasia had produced a pseudolipoma involving nearly the whole of the upper part of the breast a definite swelling was palpated near the nipple and hard axillary nodes were felt.
The finding of a pseudolipoma must be regarded as a signal that cancer is likely to be present. If the pseudolipoma is recognized directly over a readily palpable swelling and is symmetrically placed over that swelling, then the lesion is a cancer, and whatever treatment is preferred may be instituted. If the underlying tumour is diffuse or eccentrically placed, and if the pseudolipoma occupies an area much larger than that of the palpable underlying tumour, then the diagnosis can be made only by surgical exploration.

\section{Summary}

A subcutaneous swelling presenting clinically as a lipoma but differing pathologically is described, and is labelled a pseudolipoma.

The pseudolipoma has been found 21 times in a series of 480 breast conditions.

It was associated with single or multiple underlying cancers in 18 patients and with duct ectasia in three.

The mechanisms of its production by different forms of invasive cancer are described and the age incidence of the condition is explained.

Its importance as a sign of impalpable cancer is stressed and its value in the positive clinical diagnosis of cancer assessed.

We are indebted to Dr. Georgiana M. Bonser for stimulating and guiding our interest in the details of breast diseases.

\section{RBFERENCES}

Bonser, Georgiana M., Dossett, J. A., and Jull, J. W. (1961). Human and Experimental Breast Cancer. Pitman, London. Jackson, J. G., and Orr, J. W. (1957). F. Path. Bact., 74, 265.

\title{
Results of Family-orientated Therapy with Hospitalized Schizophrenics
}

\author{
A. ESTERSON,* M.B., CH.B., D.P.M. ; D. G. COOPER, $\dagger$ M.B., CH.B., D.P.M. ; R. D. LAING, $\ddagger$ M.B., CH.B., D.P.M.
}

Brit. med. F., 1965, 2, 1462-1465

This is a report on the results of conjoint family and milieu therapy with hospitalized schizophrenics at two mental hospitals in the Greater London area. During the past 10 years the internal family milieu of schizophrenics has been intensively studied by workers in the United States-for example, Bateson et al. (1956), Lidz et al. (1958), and Wynne et al. (1958)-and by ourselves (Laing and Esterson, 1964). These studies, which have shown how frequently the person diagnosed as schizophrenic is part of a network of extremely disturbed and disturbing patterns of communication, have important implications for prevention, treatment, and aftercare.

As a result of this work and that of psychotherapists with experience of prolonged relationships with schizophrenics increasing doubt has been cast on the view that schizophrenia is a medical syndrome or entity in any sense currently employed in ordinary medical practice. This work has also rationalized a form of therapy which does not focus on the individual patient but on the group or system of communications of which he is part, whether within his family or within the mental hospital.

* Research Associate, Tavistock Institute of Human Relations, London. t Senior Registrar, Shenley Hospital, Shenley, Herts.

$\ddagger$ Research Psychiatrist, Tavistock Institute of Human Relations, London.

\section{Principles of Method}

Details of our method of family and group study and treatment of the person diagnosed as schizophrenic will be described in subsequent publications.

Very briefly, the principles we have followed are: (1) A systematic clarification and undoing of patterns of communication that we take to be "schizogenic" within the family. (2) A similar clarification and undoing of such patterns of communication between patients and between staff and patients. (3) Continuity of personnel working with the family during and after the patient's stay in hospital. (4) No individual psychotherapy was given. (5) None of the so-called shock treatments were used, nor was leucotomy. Patients received comparatively small doses of tranquillizers. For instance, no male patient received more than the equivalent of $300 \mathrm{mg}$. of chlorpromazine, and $25 \%$ of patients received no tranquillizers at all. Less than $50 \%$ of the women and $15 \%$ of the men received tranquillizers during the follow-up period.

A schizophrenic who is admitted to hospital is handicapped. to a greater or less degree in his ability to live under ordinary social conditions. It is necessary to provide a social setting 
that takes this into account. We therefore reorganized the wards under our care so as to create a human context in which those transactions which our studies have shown are apt to precipitate psychotic behaviour were avoided so far as was possible. In this context each patient was ensured of a relationship with at least one other person significant to him. This relationship was as consistent and reliable as we could achieve.

To this end we trained a team of social therapists selected from the nursing staff-a social therapist being any person who sets out to establish with the patient a consistent relationship of trust. We also used patients as social therapists.

The social therapist must be ready to use almost any situation to establish a relationship with a patient. He must be frank and honest at all times and be prepared to discuss honestly any issue, no matter how personal to himself, or be straightforward in admitting his anxiety if he finds it impossible to discuss anything. Such readiness, whether in private or in a group, is crucial, we believe, to resolving the mystifying patterns of communication that surround the patient.

\section{Selection}

Our series consisted of 42 patients, 20 men and 22 women, within the ages of 15 and 35, who were drawn from two mental hospitals in the London area. Patients were selected from consecutive schizophrenics admitted into hospital according to the following criteria, which were the same for both men and women :

1. They had been diagnosed as schizophrenic ${ }^{1}$ by at least two senior psychiatrists not members of our therapeutic team, and were regarded as such by the staff.

2. They were not, and had not been, subjected to any organic condition-for example, brain injury, epilepsy-that might have affected those functions regarded as disturbed in schizophrenics.

3. They were not of obviously subnormal intelligence.

4. They had not been subjected to brain surgery of any kind.

5. Nor had they received more than 50 electric shocks in the year before the treatment began and not more than 150 in all.

6. As for the family, at least one parent should be alive and available for interview. Patients could be with or without brothers or sisters, married or single, and with or without children. They could be living with their families or on their own. No patient or family refused to co-operate. Only one woman who met the other criteria ras rejected. This was because her parents not only lived too far away (in Scotland) but they were also too infirm to travel. She was transferred to a hospital near them in accordance with administrative custom. Two of our patients were initially admitted to hospitals in other parts of the country and had been transferred to our hospitals in order to be near their families. This was standard administrative procedure and was not the consequence of our research. One man who met our other criteria was rejected because both parents were dead. Presumably the low average age of our patients accounts for the ease with which this criterion was met.

The patients selected were otherwise clinically homogeneous with the schizophrenic intake to the two hospitals. ${ }^{2}$

\section{Results}

Our results are as follows.

All patients were discharged within a year of admission. Seven $\left(17 \%\right.$ ) were readmitted ${ }^{3}$ within another year (Table I). The average duration of stay was three months. We found

TABLE I.-Patients Readmitted Within a Year of Discharge

\begin{tabular}{|c|c|c|c|c|c|c|}
\hline & & & & & No. Discharged & No. Readmitted \\
\hline $\begin{array}{l}\text { Men } \\
\text { Women }\end{array}$ & . & $\therefore$ & $\because$ & 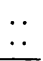 & $\begin{array}{l}20 \\
22\end{array}$ & $\begin{array}{l}2(10 \%) \\
5(23 \%)\end{array}$ \\
\hline \multicolumn{2}{|c|}{ All patients } & . & . & .. & 42 & $7(17 \%)$ \\
\hline
\end{tabular}

no significant difference between men and women in this respect, and none between those who went home or into diggings, hostels, etc.

Thirty-three patients were discharged home. The others went to live in diggings, hostels, etc. Of the seven patients readmitted, four were living at home and three away from home. Again we found no difference between the sexes in any of these respects.

Thirty-two patients were discharged to jobs: 26 worked for the whole year after discharge; two worked for less than a year but for more than six months. Once more there was no significant difference between the sexes.

Of the patients studied, 20 ( 13 men and 7 women) were first admissions. Of the 22 previous admissions 7 were men and 15 women. Three of the seven readmitted were first admissions, all women.

\section{Assessment}

In general the assessment of the results of psychiatric treatment presents great theoretical and methodological problems. This is particularly so with schizophrenia. No generally agreed method of assessing the results of treatment in schizophrenia exists, nor are there generally agreed indices of morbidity or criteria of cure.

The readmission rate is possibly the most widely accepted criterion of the continuing effectiveness of treatment, and a number of papers published in the U.S.A. have used this criterion. They report widely varying readmission rates. A study on the use of chlorpromazine carried out by Tuteur et al. (1959) showed that $20.4 \%$ of patients discharged were back in hospital within three years, while Pollack (1958), in another study on chlorpromazine, reported that of 716 patients discharged $19 \%$ were readmitted. In a group treated with tranquillizers and monthly psychotherapeutic interviews Mendel and Rapport (1963) found that $21.6 \%$ were readmitted within one year. Free and Dodd (1961), in their study of 596 patients divided into a control and an aftercare group, found that $35.1 \%$ of the former and $14.6 \%$ of the latter were back within a year of discharge. Orlinski and D'Elia (1964) reported on 13,036 discharged schizophrenics and found that $45.5 \%$ of those who received no aftercare and $25.7 \%$ of those who did were readmitted within a year.

Unfortunately, few comparable studies have been published in this country and there is no breakdown of relevant figures from the General Register Office.

A report by Renton et al. (1963), who followed up 132 men and women schizophrenics, showed that $18 \%$ were readmitted or had committed suicide within one year; while Kelly and Sargant (1965), reporting on 48 schizophrenics of both sexes treated by various combinations of E.C.T., deep and modified insulin, and phenothiazones, showed that during a two-year follow-up $42 \%$ were readmitted at least once, and $6 \%$ were leucotomized. However, these two groups may not be comparable with ours. Apart from the fact that, for example, the group studied by Renton et al. contained patients over 65 ,

1 The problem of the diagnosis, which of course enters into every report on schizophrenia, is extremely difficult, there being no generally agreed criteria or standards of reliability, regional, national, or international. For a discussion of this question see Kreitman (1961) and Laing and Esterson (1964).

$24 \%$ of all patients admitted to Shenley Hospital during the period of the research were diagnosed as suffering from schizophrenia, paranoia, or paranoid states. This compares with the figures $24 \%$ ) available from the General Register Office for almissions 24\%) available from the General Register Office for admissions In these three categories to hospitals in the North-west Metropolitan Regional Area in 1958. Figures for later years are not yet published. Failure to state the criteria, clinical or social, on which diagnosis is based and failure to give the percentage of admissions diagnosed as schizophrenic render it impossible in many cases to evaluate reports on this subiect.

Readmitted means readmitted to any hospital or psychiatric unit. In fact, none were readmitted elsewhere during the period in question. 
sampling problems tend to make comparison difficult. In the case of the study by Kelly and Sargant there is, for instance, no account of the criteria for selection, and it does not seem that the diagnosis was checked by another psychiatrist independently or by consensus. In the report by Renton et al. the group studied was selected from among hospitalized patients whose recorded diagnosis came under Schizophrenic Disorders, No. 300 (300.0 to 300.7) or Paranoia and Paranoid States, No. 303 in the International Classification of Diseases. Those who met the researchers' diagnostic criteria were chosen on the unspecified, all originally diagnosed on the basis of a clinical examination, were thus excluded. In addition it is not clear whether the decisions to exclude were checked by consensus or otherwise. Thus the group may not be representative of the patients normally diagnosed as schizophrenic in the hospital. This may have some bearing on the fact that the group included two suicides.

However, the M.R.C. team at the Maudsley have published four papers which offer us certain points of comparison. Wing et al. (1959), in a report on a group of 158 schizophrenics admitted to a London hospital in 1955-6 and discharged within two years, showed that $19.4 \%$ of the men and $30.9 \%$ of the women were readmitted within two years of discharge. However, these figures applied only to readmissions to the same hospital. Another M.R.C. report, by Brown et al. (1961), showed among other things that of 625 schizophrenic men and women admitted to three London mental hospitals in 1956 and discharged within two years, $64 \%$ were readmitted in the three years following their key admissions.

More recently the same team (Brown et al., 1962; Wing et al., 1964) have reported on a group of male schizophrenics from eight London mental hospitals who were followed up for a year after discharge. Of 128 patients, 41\% (1962 study) were readmitted within the year. When the group was reduced (to 113) by excluding those about whose diagnosis the researchers had some doubt, the readmission rate remained substantially the same, $43 \%$ (1964 study). However, these four studies, too, may not be strictly comparable with ours. For one reason the M.R.C. samples included people over the age of 35 , whereas ours did not.

The 1964 M.R.C. study is in certain respects most suitable for the purposes of comparison, but again sampling problems make this difficult. For instance, it is possible that their patients do not represent the persons diagnosed as schizophrenic by the hospital. Whereas the diagnosis of schizophrenia is established in our study by at least two psychiatrists independently within a short time of admission, in the M.R.C. study (1964) the hospital diagnosis made at the time of admisaltered in 15 out of the 128 cases by one of the team who saw basis of an examination of the case records. A number sion, when symptoms were presumably most pronounced, was

the patient for the first time just before discharge. This changed diagnosis was not checked by another psychiatrist, and these 15 patients were excluded from the final data.

We have discussed these difficulties with the M.R.C. team, who have made a further analysis of their data, to provide a group as comparable as possible to ours as a discharge group. They have not yet published these figures, but have kindly given us permission to reproduce them in this report. Taking the 1956 cohort (1961 report), they excluded those over 35 and those who had stayed for more than one year in hospital, leaving 374 men and women, of whom 193, or $52 \%$, were readmitted within the year. If this readmission group is subdivided into men and women, and first and previous admissions, we find the interesting results shown in Table II.

TABLE II.-Readmission Within One Year by First and Previous Admissions

\begin{tabular}{lll|c|c|c|c}
\hline & $\begin{array}{c}\text { First } \\
\text { Admissions }\end{array}$ & $\begin{array}{c}\% \text { First } \\
\text { Admissions } \\
\text { Readmitted }\end{array}$ & $\begin{array}{c}\text { Previous } \\
\text { Admissions }\end{array}$ & $\begin{array}{c}\% \text { Previous } \\
\text { Admissions } \\
\text { Readmitted }\end{array}$ \\
\hline Wen.. &.. &.. & 26 & $44 \%$ & 68 & $59 \%$ \\
\hline Women.. &.. &. & 30 & $42 \%$ & 69 & $56 \%$ \\
\hline All patients &.. &.. & 56 & $43 \%$ & 137 & $56 \%$ \\
\hline
\end{tabular}

If we compare our results, so far as this is possible, with those quoted in the M.R.C. studies, we find certain points of interest (Table III), although naturally we must be cautious about drawing final conclusions.

We cannot compare the readmission of men, as the number of men readmitted in our sample is too small. However, comparing the total of men and women readmitted in our sample with the number of men reported readmitted in the M.R.C. 1964 study, we find that $17 \%$ of our patients were readmitted compared with $43 \%$ of patients in the M.R.C. study, and that this difference is statistically significant $\left(\chi^{2}=8.34, P<0.005\right)$. Since the percentage of female readmissions in our study is more than twice that of males this figure may well be weighted against us.

Twelve per cent. of all patients in our group who were living at home were readmitted compared with $44.4 \%$ (men only) readmitted of those living at home in the group reported in the M.R.C. 1964 study. However, the total number of our patients readmitted is less than five, and so our figure cannot be regarded as statistically significant, although a trend emerges $\left(\chi^{2}=8.99 ; \mathrm{P}<0.005\right){ }^{4}$

\section{Discussion}

In this report we are not claiming that our approach to the problem of schizophrenia is the only one possible, or even the

'Yates's correction used here.

TABLE III.-Comparison of M.R.C. Studies with Present Study

\begin{tabular}{|c|c|c|c|c|c|c|c|c|c|c|c|}
\hline & \multicolumn{8}{|c|}{ M.R.C. Studies } & \multirow{2}{*}{\multicolumn{3}{|c|}{$\frac{\text { Our Study }}{1964 \text { Report }}$}} \\
\hline & \multicolumn{2}{|c|}{$\begin{array}{l}1959 \text { Report } \\
\text { (1955 Cohort)* }\end{array}$} & \multirow{2}{*}{$\frac{\begin{array}{c}1961 \text { Report } \\
(1956 \text { Cohort })\end{array}}{\text { All Patients }}$} & \multicolumn{3}{|c|}{$\begin{array}{c}1956 \text { Cohort } \\
\text { Personal Communication } \\
\end{array}$} & \multirow{2}{*}{$\frac{\begin{array}{c}1962 \\
\text { Report }\end{array}}{\text { Men }}$} & \multirow{2}{*}{$\frac{\begin{array}{c}1964 \\
\text { Report }\end{array}}{\text { Men }}$} & & & \\
\hline & Men & Women & & Men & Women & $\begin{array}{c}\text { All } \\
\text { Patients }\end{array}$ & & & Men & Women & $\underset{\text { Patiente }}{\text { All }}$ \\
\hline \multirow{8}{*}{ 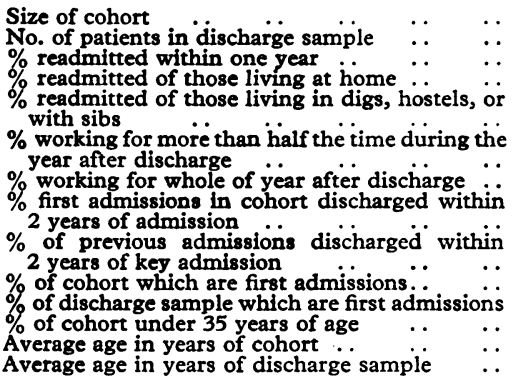 } & $\begin{array}{c}123 \\
103 \\
\text { Not given }\end{array}$ & $\begin{array}{c}75 \\
55 \\
\text { Not given }\end{array}$ & $\begin{array}{c}715 \\
625 \\
\text { Not given }\end{array}$ & $\begin{array}{r}\overline{176} \\
53 \% \\
\end{array}$ & $\begin{array}{l}1 \overline{198} \\
50 \%\end{array}$ & $\begin{array}{l}\overline{374} \\
52 \%\end{array}$ & \multirow[t]{2}{*}{$\begin{array}{c}\text { Not given } \\
128 \\
41 \% \\
45 \cdot 7 \%\end{array}$} & \multirow[t]{2}{*}{\begin{tabular}{|c|} 
Not given \\
113 \\
$43 \%$ \\
$44.4 \%$
\end{tabular}} & \multirow[t]{2}{*}{$\begin{array}{c}20 \\
20 \\
10 \% \\
6 \%\end{array}$} & \multirow[t]{2}{*}{$\begin{array}{c}22 \\
22 \\
23 \% \\
19 \%\end{array}$} & \multirow[t]{2}{*}{$\begin{array}{r}42 \\
42 \\
17 \% \\
12 \%\end{array}$} \\
\hline & & \multirow{4}{*}{$\begin{array}{l}\text { " " } \\
" \quad " \\
73 \cdot 7 \%\end{array}$} & \multirow{4}{*}{$\begin{array}{l}\text { " " } \\
", \quad " \\
91 \%\end{array}$} & & & & & & & & \\
\hline & \multirow{3}{*}{$\begin{array}{lr}" & " \\
" & " \\
93.5 \%\end{array}$} & & & - & - & - & \multirow{2}{*}{$\begin{array}{c}29 \cdot 4 \% \\
\text { Not given }\end{array}$} & \multirow{2}{*}{\begin{tabular}{|c|}
$39 \cdot 1 \%$ \\
$61.9 \%$ \\
Not given
\end{tabular}} & \multirow{2}{*}{$\begin{array}{l}33 \% \\
80 \% \\
70 \%\end{array}$} & \multirow{2}{*}{$\begin{array}{l}33 \% \\
55 \% \\
55 \%\end{array}$} & \multirow{2}{*}{$\begin{array}{l}33 \% \\
67 \% \\
62 \%\end{array}$} \\
\hline & & & & $\overline{-}$ & - & 二 & & & & & \\
\hline & & & & - & - & - & " & & $100 \%$ & $100 \%$ & $100 \%$ \\
\hline & \multirow{2}{*}{$\begin{array}{c}77.9 \% \\
37.4 \% \\
\text { Not given } \\
52 \% \\
\text { Not given }\end{array}$} & \multirow{2}{*}{$\begin{array}{c}73 \cdot 2 \% \\
25 \cdot 3 \% \\
\text { Not given } \\
42 \cdot 7 \% \\
\text { Not given }\end{array}$} & $\begin{array}{c}86 \% \\
33 \% \\
\text { Not given }\end{array}$ & $\overline{\overline{3}}$ & $\bar{z}$ & $\bar{z}$ & ", & $\ddot{25.7 \% "}$ & $\begin{array}{r}100 \% \\
65 \% \\
65 \%\end{array}$ & $\begin{array}{r}100 \% \\
32 \% \\
32 \%\end{array}$ & $\begin{array}{r}100 \% \\
48 \% \\
48 \%\end{array}$ \\
\hline & & & " & $\overline{-}$ & $\overline{-}$ & 二 & "’ & Not given & $\begin{array}{r}100 \% \\
22 \cdot 6\end{array}$ & $\begin{array}{r}100 \% \\
25 \%\end{array}$ & $24 \%$ \\
\hline & $" \quad "$ & " & & - & - & & " & & & & $24 \cdot 1$ \\
\hline
\end{tabular}

* Cohort means cohort in key admission. 
best. We are primarily concerned to show that this form of family-orientated social therapy, which has been relatively neglected in this country, is effective at least. We are thus less interested in paring down percentage figures than in showing that our results compare favourably with those reported for other methods.

In respect of readmission rate, our figures appear to be statistically much lower than the national trend, so far as that trend can be assessed. It might be suggested that the reason why so few of our patients returned to hospital was because of improved community-care services (aftercare hostels, etc.). In fact, only two of our patients were discharged to hostels. All the others returned home or went into lodgings. In all cases we provided the aftercare, which was an extension of family therapy and consisted essentially in our being available for consultation whenever the family, the patient, or the general practitioner felt the need. The average number of consultations per family in the year after discharge was three. These ranged from telephone conversations to full family discussions. Brown et al. (1962) report a significant tendency for more frequent readmission of patients who return to homes where there is high emotional involvement with a key relative. Of the five women readmitted two were not living with their families, and of the two men readmitted one was living away from his family.

As for the condition of the patients who were not readmitted, $72 \%$ of the men and $70 \%$ of the women were capable of a sufficiently reasonable social adjustment to be able to earn their living for the whole of the year after discharge.

The trends are clear. Schizophrenics now " remit" quite quickly in hospital. Most of them, however, have to return to the social context in which they broke down in the first place. In most cases this social context is the family of origin. At least $50 \%$ of first-admission schizophrenics who return to their family of origin are back in hospital within one year (so far as the national trend can be assessed). The figure rises as emotional involvement with any key member of the family becomes more intense.

For socio-economic reasons, for a long time to come, patients will have to go back to their families, who will have to put up with one another. We try to help the patient and his family to be less disturbing to each other by intensive work with the whole family, including the patient during his stay in hospital. By the time the patient is discharged they will perhaps have learned to understand one another a little better and have come to feel there is someone else who understands them. They are encouraged to feel that in any crisis they can refer back to us for an emergency family consultation either at hospital or, where hospital arrangements have allowed, in their own home. In the last five years these $\mathbf{4 2}$ families have called us out seven times in all. We arranged readmission on two occasions. Under ordinary circumstances the patient would probably have been readmitted on three of the other five occasions. Of these five cases one was a woman who needed hostel accommodation but was readmitted because none was immediately available, and four were readmitted without our knowledge. This was because we had to work within a hospital out-patient and domiciliary service in which (1) a psychiatrist unknown to the patient may see him on a routine visit to the out-patient department, (2) the family is usually never seen at all, and (3) the psychiatrist, if called on a domiciliary visit, has no knowledge of the family and has no time to acquire any.

\section{Summary}

Twenty male and 22 female schizophrenics were treated by conjoint family and milieu therapy in two mental hospitals with reduced use of tranquillizers. No individual psychotherapy was given. None of the so-called shock treatments was used, nor was leucotomy. All patients were discharged within one year of admission. The average length of stay was three months. Seventeen per cent. were readmitted within a year of discharge. Seventy per cent. of the others were sufficiently well adjusted socially to be able to earn their living for the whole of the year after discharge. These results are the first to be reported on the outcome of purely family and milieu therapy with schizophrenics, and they appear to us to establish at least a prima facie case for radical revision of the therapeutic strategy employed in most psychiatric units in relation to the schizophrenic and his family. This revision is in line with current developments in social psychiatry in this country.

We are grateful to Drs. S. T. Hayward and R. D. Scott, consultant psychiatrists at Shenley and Napsbury Hospitals respectively, for their co-operation in enabling this work to be carried out, and to the nursing staffs of both hospitals whose help was invaluable. We wish in particular to thank Mr. W. Vickers, chief male nurse at Shenley Hospital. In addition, thanks are due to Dr. A. Russell Lee and Miss Marion Bosanquet, psychiatric social worker, who participated in the work; and to Mr. Gareth Jones, clinical psychologist at Shenley Hospital for his help with the statistics. Dr. A. Russell Lee's participation was made possible through a grant from the National Institute of Mental Health, Bethesda, Maryland (MF-10579). We would also like to thank the following for their helpful criticism and advice on the preparation of this paper: Dr. E. J. M. Bowlby, Tavistock Institute of Human Relations; Dr. G. W. Brown, Medical Research Council, Social Psychiatry Research Unit, Maudsley Hospital ; Professor G. M. Carstairs, Department of Psychological Medicine, University of Edinburgh; Dr. C. M. Parkes, Tavistock Institute of Human Relations; Dr. J. H. Patterson, Medical Superintendent, Napsbury Hospital ; Professor T. Ferguson Rodger, Department of Psychological Medicine, University of Glasgow.

Dr. Laing's participation was made possible by a fellowship from the Foundations Fund for Research in Psychiatry (Grant No. 64297), while Dr. Cooper's participation was assisted by a grant from the North-West Metropolitan Regional Hospital Board for clerical help.

\section{REFERENCES}

Bateson, G., Jackson, D. D., Haley, J., and Weakland, J. (1956). Behav. Sci., 1, 251 .

Brown, G. W., Monck, E. M., Carstairs, G. M., and Wing, J. K. (1962). Brit. \%. prev. soc. Med., 16, 55 .

Fre Parkes, C. M., and Wing, J. K. (1961). f. ment. Sci., 107, 1070.

Free, S., and Dodd, D. (1961). Aftercare for Discharged Mental Patients : Conference on a Five-State Study of Mental Health in Virginia, pp. 11 and 28.

Kelly, D. H. W., and Sargant, W. (1965). Brit. med. F., 1, 147.

Kreitman, N. (1961). \%. ment. Sci., 107, 876.

Laing, R. D., and Esterson, A. (1964). Sanity, Madness, and the Family; vol. 1 Families of Schizophrenics. Tavistock, London.

Lidz, T., Cornelison, A., Terry, D., and Fleck, S. (1958). Arch. Neurol. Psychiat. (Chic.), 79, 305.

Mendel, W. M., and Rapport, S. (1963). Arch. gen. Psychiat., 8, 190

Orlinski, N., and D'Elia, E. (1964). Ibid., 10, 47.

Pollack, B. (1958). Amer. F. Psychiat., 114, 749.

Renton, C. A., Affleck, J. W.; Carstairs, G. M., and Forrest, A. D. (1963). Acta psychiat. scand., 39,548 .

Tuteur, W., Stiller, R., and Glotzer, J. (1959). Dis. nerv. Syst., 20, 512.

Wing, J. K., Denham, J., and Munro, A. B. (1959). Brit. Ұ. prev. soc. Med., 13, 145 .

Monck, E., Brown, G. W., and Carstairs, G. M. (1964). Brit. Y. Psychiat., 110, 10. Wynne, L. C., Ryckoff, I. M., Day, J., and Hirsch, S. (1958). Psychiatry,
21, 205 . 